\title{
Adapting Adaptive Management to a Cultural Understanding of Land Use Conflicts
}

Published in Society and Natural Resources, 16:435-450, 2003

Ketil Skogen, Social Research, Oslo, Norway, and

Norwegian Institute for Nature Research (NINA)

ketil.skogen@nina.no

Department of Sociology and Human Geography University of Oslo

P.O.Box 1096 Blindern

N-0317 OSLO Norway

Telephone: $\quad+4722855257$

Fax: $\quad+4722855253$

Internet: http://www.iss.uio.no 


\title{
Adapting Adaptive Management to a Cultural Understanding of Land Use Conflicts
}

\author{
KETIL SKOGEN \\ Social Research, Oslo, Norway, and \\ Norwegian Institute for Nature Research (NINA) \\ Human Environment Division \\ Lillehammer, Norway
}

\begin{abstract}
Adaptive management models are designed to include a variety of stakeholders, but they may still exclude significant groups. Drawing on two Norwegian studies of conflicts over large carnivores, one such group is identified as working-class men with strong ties to local hunting and "outdoorsman" culture. For them, the carnivore controversies are part of a conflict between dominant and subordinate cultural forms and bodies of knowledge. Representing dominant culture and hegemonic knowledge, managers and scientists have a hard time establishing rapport with anticarnivore hardliners. It is suggested that joint practical work may diminish some cultural barriers, and a project where this has been crucial is described. The lynx registration program in southeastern Norway brings together biologists, managers, and local hunters in practical field work in order to make population estimates. Although motivated by a demand for "exact numbers," this project apparently has succeeded in narrowing some cultural gaps as well.
\end{abstract}

Keywords adaptive management, culture, knowledge, land use conflicts, large carnivores, social class

Various models for resolving conflicts over land use have been developed in recent years. Common to many of these is that they attempt to integrate a range of interest groups in collaborative decision-making processes, thus (hopefully) forming new "cooperative multi-stakeholder partnerships" (Sinclair and Smith 1999; Blumenthal and Jannink 2000) and reaching consensus-based decisions. These new management approaches are improvements over older ones exclusively founded on scientifictechnical paradigms and trust in expert solutions (see Jacobson and McDuff 1998). However, many attempts at integrating multiple interest groups into decisionmaking processes appear to have limitations that may be of consequence (Selin and Chavez 1995; Gray 2000). In this article I discuss why collaborative decision-making processes may, however inadvertently, exclude some concerned groups, and I indicate one possible course of action for improving this situation.

Received 4 June 2001; accepted 9 July 2002.

This research was funded by grants from the Research Council of Norway, Environment and Development Division.

Address correspondence to Ketil Skogen, NOVA-Norwegian Social Research, PO Box 3223 Elisenberg, N-0208 Oslo, Norway. E-mail: ketil.skogen@nova.no 
Wondolleck et al. (1996, 253) point out that collaborative problem-solving efforts can often remedy some of the shortcomings of more traditional approaches to public involvement such as open hearings. The latter often reinforce existing power imbalances, partly because "citizens often have no control over meeting agendas, and they frequently are blocked by the unavailability of data and information." Nevertheless, participation in collaborative processes also presents some rather serious challenges to voluntary organizations and citizens' groups. Wondolleck et al. $(1996,252)$ state that "the drain on organizational and personal resources can be tremendous," that "citizens' groups may have to challenge well-financed, generously staffed government agencies and industries," and (referring to a study of such processes) that "participants in all cases reported the intense time demands as a problem of the alternative process, at times discouraging other citizens from participating."

The research literature indicates that stakeholder status is usually granted to organizations representing various economic interests, environmental organizations, and organizations representing other specific interest groups (Wondolleck and Yaffee 2000; Buck et al. 2001) - although there is a problem with a significant portion of the literature that it also refers to rather vague entities like "citizens groups" without explaining what kind of groups they are (cf. Wondolleck et al. 1996; Wondolleck and Yaffee 2000). Anyhow, inclusion of interest groups ensures that conflicts can be addressed at a local or regional level, incorporating stakeholders that may formerly have been left out. But research addressing the cultural dimensions of land use conflicts (cf. Dunk 1994; Kaltenborn et al. 1999; Skogen 2001a) gives us reason to suspect that the modes of work and forms of knowledge that are frequently at the core of these processes will drive some groups away from them.

Regardless of how open and innovative these processes are meant to be, they normally require representatives to work within a (more or less) formal system of committees and meetings, often for a long time (cf. Shindler and Aldred Cheek 1999). And although integration of "local" knowledge is often seen as important, scientific knowledge holds a pivotal position, to the extent that some collaborative bodies aim to generate new scientific knowledge regarding the particular issues they address (Wondolleck and Yaffee 2000). But we may safely assume that some groups of concerned people experience a strong sense of alienation toward formal modes of work as well as academic knowledge. Earlier research has shown that this is the case with many working-class people, who may also be particularly sensitive to domination by exponents of middle-class culture (such cultural forms being manifestly present in management agencies and environmental organizations alike) (Dunk 1994; Skogen 1999; 2001a; see also Willis 1977). Yet these people will often have strong opinions about resource management controversies, and may have a significant impact on local opinion climates. Consequently, from a conflict mitigation perspective this problematic is important in an "instrumental" sense: If some groups are left out, conflicts are likely to persist. But it becomes even more important when we consider that diverging positions on land use issues will generally be part of a larger panorama of societal conflicts. Dunk (1994) points out that "environmentalism and environmentalists are connotatively linked to class and regional oppositions so that they become metaphoric and metonymic symbols of other class and regional conflicts." Wilson (1997) has analyzed the reintroduction of wolves into Yellowstone, and states that "this is not really a story about wolves, but a story about people and their struggle to define the future of land use in the American West" (454). Wilson discerns three underlying social issues that shape the conflict 
panorama: (1) differential access to social power, (2) conflicting ideas about private property, and (3) divergent beliefs about humankind's proper relationship with the natural environment. Like Wilson, I use the conflict over carnivore protection as an example of land use conflicts where more is at stake than the physical consequences of this or that management regime.

\section{Large Carnivore Recovery}

The large carnivores of the Northern hemisphere seem to rouse conflict throughout their range. As Primm and Clark $(1996,1037)$ put it, "carnivores not only occupy habitat where people could be ranching, recreating, building homes, logging or drilling for oil; they also compete for game animals, some prey on livestock, and a few occasionally harm people." And while this describes very real conflicts between animals and people, the social aspects are just as pressing. These controversies clearly involve groups of people with strongly diverging interests. Basically, some people want the predators removed because they threaten economic interests or even lifestyles, while others see them as vital parts of a wilderness that is shrinking all too rapidly. Some dimensions of these conflicts are easy to comprehend: for example, those that concern threatened economic interests or leisure activities. But most controversies appear to be more complex than this (Wilson 1997; Skogen 2001a), and yet there has been limited focus on their less obvious aspects.

Various adaptive approaches may probably to some degree accommodate economic and practical considerations raised by organizations representing such groups as livestock farmers, landowners, and hunters. But this is scarcely sufficient to secure legitimacy in all groups, and deficient recognition of the conflict's cultural dimension is one important reason for this. Some groups that harbor strong feelings and may engage heavily in the conflicts are not affected economically, and the practical consequences of carnivore presence may seem limited (for example, having to adjust hunting methods). Furthermore, cultural factors may amplify - or, in some cases, subdue - the aggressiveness of the stance taken by actors whose economical interests are affected. Management regimes and the processes that are associated with them will be assigned symbolic meanings and may therefore attain a wider significance, as will groups of actors that are involved.

I pursue these issues in the following manner: In the next section I look at some results from two studies conducted in the county of Hedmark ${ }^{1}$ in southeastern Norway. Both address people's relationships to nature in general and to land use issues in particular. The focus remains on some possible consequences for management approaches - mainly through identification of groups that fervently oppose current carnivore protection, and that are difficult to involve in current management practices, collaborative or otherwise. In the subsequent section, I discuss some experiences from a project where old adversaries have been brought together in practical cooperation. This discussion is based on interviews with key informants from involved organizations and agencies, in addition to everyday observations and articles in local newspapers from one of Norway's high-conflict areas over a 10-year period.

\section{Background on the Hedmark Studies}

The two studies were designed to probe the relationship between diverse - and changing - cultural patterns and attitudes towards nature and land use within rural 
communities. One was a qualitative study of young people conducted in the municipality of Trysil in 1999. The other is a large qualitative research project in two communities in the same region that started in 2000, and where data from one locality (Stor-Elvdal) are now available. None of the two studies had management practices or collaboration as a particular focus at the outset, nor were they designed as studies of the carnivore conflicts as such, but it turned out that both yielded data that are relevant to the issues that I want to address here.

\section{The Carnivore Conflicts}

The carnivore conflicts have a long history in Hedmark, particularly regarding brown bear and lynx. The problem that has received most attention is livestock depredation, which has seriously affected the rough grazing of sheep. Trysil was one of the first battlegrounds when the Norwegian brown bear population started its slow recovery some 25 years ago, and eventually the bears caused problems for farmers in Stor-Elvdal too. Lynx have also been a source of conflict in both communities, due to livestock losses and competition for game, primarily roe deer. Wolverines regularly kill sheep in mountainous Stor-Elvdal, while it is rarely seen in lowland Trysil. However, it is the newly arrived wolves that have really caused commotion. In 1999 two wolf packs settled in Stor-Elvdal. They have since killed sheep and dogs, and appear to have had a significant impact on the moose population in some locations. Moose hunting is very important in this region, as are other forms of hunting with untethered dogs. And hunting dogs entering wolf territories on their own often face a rather bleak fate. Wolves have been observed only sporadically in Trysil, but the bears and lynx get much less attention now that the wolves are expected to move in from neighboring areas, such as Stor-Elvdal.

\section{Trysil}

The Trysil study was designed to address the changing relationships to nature in rural areas that are presumably driven by economic and cultural modernization. In the absence of time-series data, this qualitative study focused on young people, who were thought to be most susceptible to such forms of social change (see Skogen 2001a).

Trysil was selected as a research locality because it is economically diverse with a large tourist industry (mainly skiing resorts) as well as the more traditional sectors of forestry and livestock farming. The tourist industry is concentrated in the center of the municipality, where about half of the total population of 7500 lives. There are several smaller communities, which have retained close ties to traditional resource extraction. Thus, different segments of the population, and different areas within the municipality, may be taken to roughly represent degrees of modernization.

Data were collected through focus group sessions and interviews with individual informants. There were 31 informants altogether, representing a range of background factors, educational aspirations, and leisure interests; 26 were interviewed in 7 focus groups and 5 were interviewed separately. Most of them were between 16 and 20 years old. In addition, 11 adult informants were enlisted, but the interviews with them were somewhat more superficial. Given the focus of the study, the main aim here was to acquire background knowledge about the community and to establish guidelines for selecting youth informants. However, these 11 interviews also provided interesting information on the social construction of the carnivore situation in Trysil. 


\section{Stor-Elvdal}

The Stor-Elvdal study is a large qualitative project that started in 2000. This study focuses on land use conflicts in rural areas generally and the social and cultural factors that constitute axes of differentiation in this field. The project rests on the hypothesis that social factors such as gender, age, social class, and education are relevant for the understanding of diverging systems of meaning, and that such factors interact with economic and cultural modernization and degrees of urbanization. It aims to challenge and nuance the importance of the urban-rural dimension through improved understanding of the dynamic nature of the social production of meaning regarding land use and resource utilization, particularly within rural communities.

The municipality of Stor-Elvdal is situated in the same region as Trysil, but is smaller (population approximately 3000) and more dependent on traditional resource extraction. Logging and timber industry have always been pillars of the local economy. Livestock farming also plays a part, and sheep herding is of a certain importance in some small communities. There are some extremely large forest properties in Stor-Elvdal, and most of the owners, who are very wealthy, live in the municipality. Thus, Stor-Elvdal bears the distinct marks of a class society, even today.

There were 74 interview sessions, including a total of 88 informants. Four sessions were conducted as focus groups with upper secondary school students (the same age group and the same approach as in Trysil), and two interviews were conducted with married couples. The rest were individual interviews. The informants were recruited from all age groups from 16 upward, and represented a wide range of socioeconomic, educational, and sociocultural groups. Different links to nature use were represented, such as grazing, lease of hunting rights, hunting, new forms of nature tourism, and general recreation, as well as lack of any particular interest in nature. Interviews were semistructured, focusing on various aspects of the local community and on people's relationship to nature and land use.

\section{Local Diversity}

Contrary to popular images of such communities as unified against "predator invasion," the studies in Trysil and Stor-Elvdal demonstrated that all typical views of the carnivore issue were present. Some felt that there were far too many large carnivores, some supported the current management regime, quite a few were indifferent, and others wanted more carnivores, if necessary at the expense of livestock and huntable game. Procarnivore attitudes and indifference appeared to be more common in Trysil than in Stor-Elvdal. This could reflect the stronger dependence on resource utilization and commercial leasing of hunting in Stor-Elvdal, as well as the recent appearance of wolves. However, one should bear in mind that the Trysil data were collected from young people, among whom there are probably fewer with a strong attachment to the economic and cultural positions that entail a clear negative opinion of large carnivores and the current management regime (Skogen 2001a).

\section{Traditional Hunters and Wolf Recovery}

We now take a closer look at the findings, focusing on aspects that are relevant for management approaches. A more comprehensive presentation of the Trysil findings and theoretical discussions of them can be found elsewhere (Skogen 2001a; 2001b; 
2001c). The present article is the first scientific publication based on the material from Stor-Elvdal.

I focus on a group that is strongly engaged in the carnivore issue but that normally does not have major economic interests at stake. In both studies, a significant portion of the carnivore adversaries were found among working-class men with a strong attachment to a traditional lifestyle close to nature, particularly through hunting. In the Trysil study, aggressive carnivore resistance was found almost exclusively among young men with a working-class background, most of whom were also heading toward working-class occupations themselves. In StorElvdal, deep skepticism toward current carnivore management was found in many segments of the population, but the most impressive concentration of strong feelings prevailed among working-class hunters. ${ }^{2}$ The concrete issues these men focused on were the loss of hunting dogs and the decline in some game species, primarily moose and roe deer. The presence of wolves forced them to hunt less and in new places. Popular hunting methods based on the use of untethered dogs were now seen as impossible. Even training the dogs had become risky. As the hunting and the dogs were extremely important to them, indeed a main reason for living in the area, it is not difficult to understand their frustration. However, as we show presently, there was rather more to it than this.

These men were strongly attached to their community and to the land. In several respects they kept up a traditional way of living that has been typical for men in rural areas, which entails largely manual work and a somewhat rough contact with nature. They were firmly rooted in what we might term a production-oriented culture: cultural forms that are typical of workers and farmers, comprising high valuation of practical work, technical ingenuity and masculine toughness, and a deep skepticism toward academic knowledge and intellectual pursuits (see also Dunk 1991; 1994; Skogen 1996; 2001a; 2001c). Many seemed to have a clear image of themselves as successors of earlier generations of hunters and woodsmen. The following quotation is from a 19-year-old hunter, fisherman, and outdoorsman from Trysil, with a working-class background but now undergoing academic training. This informant actually had moderate opinions about the carnivore issue, but being rather verbal, he nicely captured the essence of an outdoorsman culture where negative attitudes to carnivores were typical.

Int.: OK, so what do you do when you're out?

We live as huntsmen [using the archaic Norwegian term veidemannsliv to actively connote deep tradition]. A little old-fashioned, perhaps. Often we go ice fishing [the interview took place in midwinter]. We follow the seasons - all kinds of things! In the winter we fish, and often go for longer trips into the mountains to fish for mountain trout. Sleeping outdoors. In the summer we sleep outdoors too, or we spend the nights in old logging cabins. We fish. And in the fall there's nothing but hunting, all possible kinds of hunting. Everything from birds and hare to moose.

This passage conveys a picture of a life very close to nature, or indeed in nature. Accordingly, these informants had a substantial knowledge of nature and wildlife, and they were concerned about protecting the land. For example, most informants who brought up current logging practices as a problem were found in this group. They also revealed a knowledge of the ecological harm that logging may cause that was equaled by very few other informants. The following quotation is from a 
29-year-old man from Stor-Elvdal, with a working-class background and a workingclass occupation.

I don't agree with this logging they do, and that's because I'm interested in using the forests around here. I don't like the clear-cuts. They think too much about money, they don't think about the future and that the forests should be there for their children too. They cut way too much compared to what they should do. Now they're logging the places where I used to find moose, and the hunting is no good any more. ... I don't know too much about it, but I want to be able to keep hunting and fishing the way I am used to, and that's why I don't like the logging. Besides, it gets so ugly when they use this heavy machinery. It was better before, when they had loggers working here, then it didn't get so damned ugly. Now, they'll have the big machines go in and do everything. ... I think they take out more timber than before. They say the opposite, but I don't believe it. Some of the clearcuts are huge and the damage is serious. It's way out of control. OK, we have large forests here, but we want to have some left too. And they should know that trees don't grow so damned fast!

However, they would never label these concerns environmental. Although the same views regarding modern logging practices are found among environmentalists, there is a formidable cultural barrier between these young hunters and the environmental movement (see also Dunk 1994). In fact, they were just as angry at environmentalists and wildlife biologists (roughly perceived as the same group) as at the predators themselves. They firmly held the opinion that biologists know that the carnivore populations are much larger than they claim, and that many environmentalists are simply crazy. They also felt that city people generally have far too much power, and are now using this power to turn rural Norway into a game preserve. Due to ignorance and indifference on the part of powerful organizations and government agencies based in urban areas, the voices of local people are not heard. Here are some statements about biologists made by a 32-year-old avid hunter from StorElvdal. He had a working-class background, and in order to stay in the area he loved, he now did unskilled work in both the public and private service sectors.

I don't understand what they want. I really don't understand it! They don't see the problem. They sit and write on a sheet of paper and read in some books they have... and they do this research on how many moose the wolves kill, and so on, but they really would have to come here to experience things....

Int.: Do you think that the scientific community recognizes your kind of knowledge and experience?

No, I don't think they pay any heed to it. I really don't. I think they should take a few trips and listen to what local people say. After all, many people here are out in the woods every day doing something or other. They see much and get a lot of experience. ... Not that we have a perfect knowledge of wolf behavior, but we do know ... many of us will know other things than the scientists know.

Underlying such views is an experience of being subject to patronizing attitudes from people who do not know these areas, and that lay knowledge is not taken seriously. 
Seen in this perspective, the dominant discourse of carnivore protection is a typical instance of middle-class efforts to shape and correct the opinions, attitudes, and practices of working-class people. Such a relation of cultural power, often very visibly related to parallel relations of economic and political power, will obviously affect communication between people rooted in separate cultural contexts (Dunk 1994; Skogen 1996).

The social construction of the urban-rural conflict axis also plays a part here. Those groups, institutions, views, indeed, ways of life that are perceived as threatening or disturbing, undermining fundamental interpretations of nature and even "the world at large," are more prominent (and thus more visible) in urban areas. This sense of cultural conflict blends with the experience of economic centralization, decline in farming and resource extraction employment, depopulation and reduction of public as well as private service provision - and of course with the concrete experience of mutilated dogs, less huntable game, and dead sheep. Therefore, urban people, urban culture, and indeed cities as such are near at hand as symbols of the forces behind the problems rural people have to face. Here is the same informant whose words were just quoted:
Int.: Nordmarka [popular recreational area outside Oslo] is now within the zone where wolves are accepted...
I think that's good, excellent! I hope there will be many wolves down there! Int.: Why?
Well, then they can eat some of those poodles that run around down there. City ladies who don't know anything think that it's all very well to have wolves up here, for us "northerners" to handle. Then they will get something to cope with!

It is a widely held view that social change will lead to movement from "traditional" to "modern" cultural forms. Limited attention is paid to the opposite tendency: consolidation of traditional patterns as a form of resistance against processes of social change that are perceived as detrimental. There is much to indicate that traditional activities like hunting are now built into more clear-cut cultural constellations than before-for example, in contrast to more distinctly modern cultural tendencies (Skogen 2001c). And this is probably a significant side effect of modernization: the active choice of tradition in the face of ominous change. The carnivore conflict is thus part of a larger picture of clashes between subordinate and hegemonic forms of knowledge, and subordinate and hegemonic sociocultural constellations. The cultural diversification inherent in modernization does not necessarily erase these antagonisms; it may in fact accentuate them.

\section{The Modifying Forces of Modernization}

It is important to note, however, that modifying forces were at work, entailing a diversity of attitudes among the hunters. The hard-core carnivore opposition was most prominent in groups delineated primarily by the factors I have outlined. But many hunters did not have a working-class background, and did not identify strongly with local traditions of resource utilization and land use. Even among those with a working-class background, factors that appeared to modify the harsh views on large carnivores were higher education (choice of academic programs in upper secondary school in the case of the Trysil youngsters) and what we might term a 
general "outward orientation," and not least identification with scientific knowledge, as opposed to local, lay knowledge. This latter factor was of course closely tied to having obtained higher education. Hunters and outdoorsmen with such orientations often seemed to think that carnivores should be present in substantial numbers, yet they were critical of "extremist" environmentalism. Here is an example of a typical "reflected and responsible" position taken by a 20 -year-old hunter, fisherman, and athlete from Trysil, who (like the previous Trysil informant) comes from a workingclass background but is in academic training himself:

Yes, I know that many have strong opinions about this matter. For my part ... I want a Norwegian fauna with productive populations of all kinds of predators, I really do. But I do understand that many people-perhaps especially hunters - take a more aggressive stance, that they want fewer predators, because of the pressure on the game, and that they have to slow down on the hunting, perhaps. All right, they want as much game to hunt as possible. But Norwegian fauna must have predators, I want them. If necessary, we must hunt a little less.

\section{The Links to Management}

Such views are very much in line with the official position of the Norwegian Association of Hunters and Anglers (NJFF). NJFF has ambitions to be taken seriously as an organization that cares for the environment, is an important actor in resource management issues, and has a serious working relationship with the environmental authorities, at the national, regional, and local levels. Therefore, people who hold these moderate views are most likely to represent the hunting interests in collaborative management forums where organizations such as NJFF are represented, even if these are established regionally. This is due to a combination of selection to organizational activism and socialization through organizational work. Such processes have been described for example in connection with the so-called "institutionalization" of the environmental movement (cf. Seippel 2001). Organization officials and activists will regularly relate to management issues and agencies, and their perspectives are necessarily influenced by this form of integration in what we might term a management discourse. Although there may be considerable differences in emphasis regarding basic political issues as well as in the interpretation of concrete situations, there is generally a common conceptual ground which appears to provide a familiar and comfortable frame around the exchange of diverging opinions. It is important to keep in mind that this "latent consensus" stemming in part from the socialization of organization activists within a field of "civic practices" may often be a sound foundation for making joint decisions.

But even if there is a viable foundation for decisions that actually accommodate a broader range of concerns than before, there is a noticeable distance between the perspectives these activists endorse and the views and attitudes held by many rankand-file hunters and outdoorsmen. The cited studies demonstrated that their hostility was also directed toward academics, scientists, and managers, and indeed toward talking (as opposed to doing) as a means of obtaining results. Group discussions and formal meetings as a path to consensus may not be well suited to a culture where anti-intellectualism and antiformalism are central traits, and where subordinate (lay, practical) forms of knowledge prevail in direct opposition to dominant (academic, scientific) forms of knowledge and dominant (middle-class) cultural forms. 
There is good reason to believe that the latter generally dominates the mode of work in committees, in councils, and even in open, public meetings.

Thus, there is a need for even more flexible approaches to management controversies, aiming to include groups that are not necessarily seen as "interest groups" in their own right. In particular, there is a need for approaches that incorporate nonscientific forms of knowledge and are based on practical work, thus accommodating central cultural traits found in groups that hold strong opinions not only on carnivores, but also on biologists, environmentalists, and managers. Such efforts should not be seen principally as pedagogically motivated, in the sense that it is a question of winning lay people for true scientific knowledge. They should lead not only to reduced friction, but hopefully also to a real triangulation of available knowledge - to the benefit of all parties.

\section{The Lynx Registration Program}

We now turn to a project where practical cooperation has been crucial, and that appears to have succeeded in narrowing some gaps - although this was not the principal objective in the first place. The lynx registration program in Hedmark brings together biologists, managers, and hundreds of local hunters in an annual effort to estimate the county's lynx population.

A caveat is in order here: The following account of the lynx registration program is based on interviews with key personnel, ${ }^{3}$ and on observations and newspaper articles from the last decade. There have been no systematic efforts to interview volunteers who have participated. Thus, we have to be careful when drawing conclusions. The aim here is not to demonstrate that this approach will always lead to a reduced conflict level, but to indicate a course of action that appears to be promising in the light of the arguments presented earlier, and that should be investigated more thoroughly through further research.

Dispute over the actual number of individuals in a particular region is a core element in the conflict over large carnivores. Many local hunters roam the forests and mountains all year round, and they frequently claim that biologists seriously underestimate the carnivore populations. In their view, this again leads to more restrictive protection than necessary. This has come to be a chief concern in the dialogue between the regional environmental authorities in Hedmark ${ }^{4}$ and the Hedmark section of NJFF (NJFF-H). That organization experiences a massive pressure from its members in areas with above-average predator populations, who urge a more aggressive stance toward the current protection policy. However, members are not united on this issue (particularly not if one sees the county as a whole), as quite a few appreciate the return of the predators and savor what they perceive to be an improving ecological condition, even hoping to get a glimpse of lynx or bear on a hunting trip. Furthermore, hunters have increasingly come to appreciate lynx hunting as sport, and this will of course require viable lynx populations. Experiencing such cross pressure, and given the political ambitions of the organization at a national level, a logical strategy for the board of NJFF-H has been to claim that we all know too little about the size of the populations, and that we therefore need more effective means of making population estimates.

In the early 1990s lynx hunting was legalized within a strict quota system in Norway, following a period of total protection. One element in establishing a regional management model was to set these quotas on a year-by-year basis using a committee at the county level. This committee has representatives from several 
organizations, including NJFF-H, and is an attempt at collaborative management. In order to have a sound basis for decisions, the committee needs as good data as possible about the size and structure of the lynx population. Therefore NJFF-H also has an interest in obtaining the best possible foundation for setting the quota for a hunt in which many members participate - the most important factor was not to set it too low.

This was the background for launching the lynx registration program. It is a cooperative effort involving county level management as well as research biologists, but the staple element is the efforts of some 700 volunteers. Most of these are members of NJFF-H. The initiative originally came from that organization, although technically NJFF-H now arranges the registrations on behalf of the Department of Environmental Affairs (DEA) at the county governor's office.

Essentially, the project has been organized in the following manner: One day every winter (if snow conditions allow, which to the most part they do), large areas in Hedmark are traversed along fixed transect lines in search of lynx tracks. The registration shifts between different parts of the county from year to year. All tracks from large carnivores are registered, so valuable data are gathered concerning the other species too. The operation is jointly planned by the cooperating parties, which in recent years have been the Norwegian Institute for Nature Research (NINA) and Hedmark College, in addition to NJFF-H and the DEA. The biologists from the research institutions play an active part in verifying and evaluating observations. They also write the reports together with the managers and NJFF-H officials.

Even though the focus always remains on obtaining good data, there is a growing awareness of the social "spin-off" effects - so much so that these appear to be entering center stage, at least in the perspective of NJFF-H. The following account deals with what NJFF-H experiences as changing attitudes on the part of management agencies and scientists. It came from an official who has played a central role in planning and organizing the operations since the beginning:

This year we raised half the funding we needed in advance. Then NINA and the college took a very active initiative toward the Directorate for Nature Management, ${ }^{5}$ and then we had the rest of the money in almost no time. They have seen the great benefits of this type of registration activity, not only to obtain the "exact numbers"-in quotation marks - for the populations, but to involve local people and to reach out to the local level.

And here is an employee at the DEA who has handled the project for that agency. $\mathrm{He}$ is a little more reserved, but nevertheless acknowledges the social dimensions of the project:

And if you bring a lot of people out to make their own observations, I think that...well, even if there certainly are different opinions among the participants regarding how interesting this is, they do feel that they are taking part in the registration. And you should definitely not overlook that part of it.

All track observations made by the volunteers are subsequently examined by trained personnel. This can be the biologists or managers, but mostly it is the so-called "carnivore contacts." They are experienced trackers who are hired on a part-time basis by the DEA, and who have also been trained to assess damage to domestic 
animals caused by protected carnivores (such assessment being a prerequisite for compensation). Some of these people have an education in nature management, and some have not. However, they have intimate knowledge of the areas in which they work, and they represent an important link between local people and the nature management apparatus. The attitudes toward local, practical knowledge that the carnivore contacts display will of course play an important part in shaping the corresponding attitudes of many local people toward managers in general and the DEA in particular.

The carnivore contacts have a crucial role in the big registrations. It is mostly they who check the observations made by volunteers, and who thus represent the official system: the institutions of management and research. This means that volunteers meet these institutions as represented by trained locals. In most cases, those who made the observations are present when the experts arrive. At this point, basically two things can happen: Either the observation is confirmed (the expert agrees that the tracks are left by the species the observer suspected) or they are dismissed as something else (the expert claims that the tracks are anything from jumping squirrel to moose). In the latter case, much depends on the way this message is conveyed to the observer. Chances are that the local carnivore contacts may do this in a less provoking manner than some scientists and managers have been known to. This is how the NJFF-H official viewed the situation:
Int.: But when the observations made by rank-and-file participants have to be confirmed by somebody else... has this always gone smoothly, or what?
No, there have been problems, especially in the beginning, when people felt that their observations were doubted. ... But I think this has improved gradually, and that has a lot to do with the way the carnivore contacts behave when they arrive at the site and start tracking. It is very important that those who have made the observations in the first place are there too, so they can participate and discuss things when their observa- tions are being evaluated. ... Of course, people have been a little sore when their "wolf" turned out to be a dog. ... So what we have been wanting to do, is to arrange local tracking courses, so more people could be trained and so we would minimize these episodes, but we haven't got around to it yet.

Some research biologists also take part in the process of checking observations, but being fewer and using less time, they do not encounter as many volunteers. However, the following quotation is from an experienced wildlife biologist at Hedmark College:

If we look at the areas where we have wolf packs, two-thirds of the reported track observations that we check turn out not to be from wolves. In those situations it is important to involve the person who made the observations and discuss it. And if we don't agree, the good thing about snow is that it never lies, and we can follow the tracks until we do agree. ... If we think that it is a dog, but the fellow who reported it still thinks it's a wolf; OK, fair enough, then we go on until we find ... for instance the place a car parked and let the dog out or even into a farm yard and find the dog itself. ...

Int.: But doesn't it happen that it really is a wolf, even if you were doubtful at first? Oh, yes, it definitely does! 
As we have seen, the lynx registration program was initially motivated by the need for "accurate estimates," and this is still the official reason for going through with it. From the viewpoint of NJFF-H, this could be construed as a contestation of the population estimates presented by the biologists. But it is simultaneously an acceptance of the "scientific" basis for these estimates. That is, quite a few hunters set out to prove (complying with scientific principles, if sometimes a little reluctantly) that they are right and that the biologists are wrong. And although no dramatic adjustment of population estimates has happened, scientists and managers acknowledge the value of controlling estimates based on other types of data, and also discovering animals in new areas. Here is the wildlife manager cited earlier on this issue:

Concerning the lynx, even if we arrive at approximately the same numbers as we had in advance, that's a result, too. It is an important corroboration of our estimates. ... And concerning the wolf ... these large registrations where people cover very large areas and provide a snapshot of the situation, will help us discover if wolves have settled in new areas.

And the research biologist:

Int.: Has anything come out of these large registrations that you consider scientifically valuable?

Yes, very much so! There are many different methods for surveying carnivore populations, and you will arrive at slightly different numbers depending on the method, and coincidence concerning the weather and the whereabouts of the animals on a particular day, and so on. So the more different methods you employ, the better picture you get of what is really out there.

From the scientists' and managers' point of view, getting local people to trust the conservative population estimates based on conventional research methods would be a great benefit. They also seem to believe that this is a likely outcome. Here is our manager talking again:

There are always rumors that there are wolves in places where we have no confirmed observations .... people are convinced that wolves have settled near their communities. ... If no wolves are found during these large operations, except where we expect them, then we may indeed kill these rumors. So I have concluded that these registrations are important in a county like Hedmark.

In all probability, some people will actually accept the evidence and concede that the wolf population may have been overestimated by ordinary folk, while many hardliners will find explanations for why animals escaped observation. Anyhow, the most important gains from the project may not be the population estimates, but the teamwork itself. There are indications that the relationship between local hunters and biologists and managers has improved perceptibly over the last few years. This is of course not only due to the lynx project, but biologists appear to have changed their attitudes toward "locals" and seem to take local knowledge more seriously. They also seem to put more emphasis on keeping in contact with local people, having 
obviously recognized the twofold benefits: Local people actually posses valuable knowledge, and keeping in contact with them can take the edge off their critical attitudes toward scientists. Although this is not a development originating from the lynx project alone, and although some researchers are more concerned about local participation than others, it appears that the lynx project has contributed towards shifting the position of the scientific community on this issue.

The NJFF members experience that they take part in establishing knowledge about the carnivore situation: knowledge that is taken seriously by scientists and managers. Furthermore, their understanding seems to be that NJFF is not drawn into the scientists' project, but essentially the other way round. This is important for people's feeling of who the project belongs to. And this again is important because much of the dispute is about who shall have the power to put together the "correct" picture of the carnivore situation. The method of registration, which entails long skiing or snowmobile trips, that is, actually spending a lot of time in the forest, corresponds nicely to the principles of knowledge accumulation that are central to the working-class culture discussed earlier. Actually, many biologists do this all the time anyway, and regard it as essential to their methodology, but many people do not believe that this is the case. The hunter cited earlier, who thought that scientists rarely leave their desks, expressed a common view. Therefore, supplying data derived from hard work in the field may be seen as something new, and as a unique contribution that only "practical people" could deliver-and, given the scale of the operations, this is may indeed be true.

\section{Concluding Discussion}

If adaptive management is to be truly adaptive, it should take into account not only the particular, concrete conflicts of interest involved in a given land use controversy, but also the larger societal mechanisms that these conflicts enter into. The stance people take on land use issues is influenced by many factors, and some of these may only partially or indirectly originate from the actual subject matter of the conflict (Wilson 1997). To understand the driving forces behind these disputes, it is therefore necessary to have a broader scope, and not least take culture and cultural power relations into account.

As we have seen, it is entirely possible to develop sensible approaches based on ordinary common sense. But, as we have also seen, the relative success of the lynx registration program in the social realm cannot be attributed to deliberate planning. This is definitely not unique; many collaborative efforts have been driven by ordinary people's urge to simply "get things done" (Wondolleck and Yaffee 2000). In many cases things have gone well without any influx from social science, but such processes may also be hampered by their inability to include, or even appeal to, some concerned groups. Social science should have a role in remedying this situation through indicating approaches that incorporate social objectives from the outset. As pointed out by Endter-Wada et al. (1998), social science is essential to ecosystem management because understanding human interaction with nature is paramount to understanding the ecosystem themselves, but also because there is currently a drive toward "greater public involvement in decision-making and in formulating policies and strategies for ecosystem management" (892).

The type of collaboration discussed in this article does not involve participants in decision-making as such, and the participation itself will not give them direct influence on management regimes. However, the basis for decision making could be 
improved in two ways: by the impact on some of the nonmaterial aspects of the conflict and by actually strengthening the biological "knowledge base."

Barriers against collaboration - at least against taking it too far-exist also among managers and biologists. Although there is a growing understanding that the social aspects of nature management must be addressed, there is still reluctance to stray too far away from "hard biological facts" as a basis for management. Projects that aim to produce such facts in a semiscientific way are possibly easier to accept than efforts to include local, lay knowledge that may go against established scientific knowledge at a given point in time.

There are examples in the literature of practical field activities being emphasized as a means to develop common frames of reference and personal trust. However, this seems to reflect a general recognition of the pedagogic effects of practical work: If people work together, they learn to know each other, regardless of who they are (cf. Wondolleck and Yaffee 2000). The potential for diminishing knowledge gaps of cultural origin and for approaching groups that may have been alienated from the more formal forms of collaboration seems to have received little specific attention.

Obviously, carnivore population assessment cannot eliminate conflict, regardless of how it is organized. Indeed, given the diverging material interests, power imbalance, and cultural cleavages that fuel these conflicts, we should probably set ourselves rather modest goals. The type of undertaking described in this article may, however, help actors with different and conflicting perspectives to develop forms of understanding with growing areas of overlap. This would obviously be a step in the right direction, and similar approaches to other management controversies should not be too hard to device.

\section{Notes}

1. A Norwegian "county" is an administrative and geographical unit at an intermediate level, between the national government and the local municipalities. The county of Hedmark covers $27,388 \mathrm{~km}^{2}$, and is divided into 22 municipalities with a total of 187,000 inhabitants.

2. I must stress again that this is just one group of "adversaries," but one where strong economic interests are typically not present. While this article focuses on certain cultural dimensions of the carnivore controversies that may help to explain the attitudes found in this group, the attitudes of those who do have economic interests at stake are of course also affected by cultural factors. However, this is beyond the scope of the article.

3. One NJFF official, one DEA employee, and one research biologist from the regional college.

4. The national government has institutions that cover the counties as geographical units. These "Fylkesmenn" (offices of the county governors) are responsible for environmental protection and many aspects of land management at the county level.

5. Which fund the Department of Environmental Affairs at the Office of the county governor.

\section{References}

Blumenthal, D., and J. L. Jannink. 2000. A classification of collaborative management methods. Conserv. Ecol. 4:13. [online] http://www.consecol.org/vol4/iss2/art13

Buck, L. E., C. C. Geisler, J. Schelhas, and E. Wollenberg. 2001. Biological diversity. Balancing interests through adaptive collaborative management. Boca Raton, FL: CRC Press.

Dunk, T. W. 1991. It's a working man's town. Male working-class culture. Montreal: McGillQueen's University Press. 
Dunk, T. W. 1994. Talking about trees: Environment and society in forest worker's culture. Can. Rev. Sociol. Anthropol. 31:14-34.

Endter-Wada, J., D. Blahna, R. Krannich, and M. Brunson. 1998. A framework for understanding social science contributions to ecosystem management. Ecol. Appl. 8:891-904.

Gray, A. N. 2000. Adaptive ecosystem management in the Pacific Northwest: A case study from coastal Oregon. Conserv. Ecol. 4:6. [online] http://www.consecol.org/vol4/iss2/art6

Jacobson, S. K., and M. McDuff. 1998. Training idiots savants: The lack of human dimensions in conservation biology. Conserv. Biol. 12:263-267.

Kaltenborn, B. P., H. Riese, and M. Hudeide. 1999. National park planning and local participation: Some reflections from a mountain region in southern Norway. Mount. Res. Dev. 19:51-61.

Primm, S. A., and T. W. Clark. 1996. Making sense of the policy process for carnivore conservation. Conserv. Biol. 10:1036-1045.

Seippel, Ø. 2001. From mobilization to institutionalization? The case of Norwegian environmentalism. Acta Sociol. 44:123-137.

Selin, S., and D. Chavez. 1995. Developing a collaborative model for environmental planning and management. Environ. Manage. 19:189-195.

Shindler, B., and K. Aldred Cheek. 1999. Integrating citizens in adaptive management: a propositional analysis. Conserv. Ecol. 3:9 [online] http://www.consecol.org/vol3/iss1/art9

Sinclair, A. J., and D. L. Smith. 1999. The model forest program in Canada: Building consensus on sustainable forest management? Society Nat. Resources 12:121-138.

Skogen, K. 1996. Young environmentalists: Post-modern identities or middle-class culture? Sociol. Rev. 44:452-473.

Skogen, K. 1999. Another look at culture and nature: How culture patterns influence environmental orientation among Norwegian youth. Acta Sociol. 42:223-239.

Skogen, K. 2001a. Who's afraid of the big, bad wolf? Young people's responses to the conflicts over large carnivores in Eastern Norway. Rural Sociol. 66:203-226.

Skogen, K. 2001b. Risiko i et trygghetssamfunn. En hverdagshistorie fra Trysil. (Risk in a safe society. An everyday story from Trysil). Sosiol. Tidssk. (Norwegian J. Sociol.) 9:211-232.

Skogen, K. 2001c. Friluftsliv som seismograf for sosial endring: Jegere og snowboardere i det seinmoderne (Outdoor recreation as a seismograph for social change: Hunters and snowboarders in the late modern era). In Ungdom - lokal og global (Youth-Local and global), eds. K. Heggen, J. O. Myklebust and T. Øia, 56-67. Oslo: Det Norske Samlaget.

Willis, P. 1977. Learning to labour: How working-class kids get working-class jobs. Aldershot: Gower.

Wilson, M. A. 1997. The wolf in Yellowstone: Science, symbol, or politics? Deconstructing the conflict between environmentalism and wise use. Society Nat. Resources 10:453-468.

Wondolleck, J. M., N. J. Manring, and J. E. Crowfoot. 1996. Teetering at the top of the ladder: The experience of citizen group participants in alternative dispute resolution processes. Sociol. Perspect. 39:249-262.

Wondolleck, J. M., and S. L. Yaffee. 2000. Making collaboration work: Lessons from innovation in natural resource management. Washington, DC: Island Press. 